\title{
Practice and Thinking on Construction of Tianjin Binhai Agricultural Science and Technology Park
}

\author{
Xia Yang ${ }^{1 \mathrm{a}}$, Jinghui Yang ${ }^{2 \mathrm{~b}}$, Qiaoli Zhang ${ }^{1 \mathrm{c}}$, Yanjun Liu ${ }^{2 \mathrm{~d}}$ \\ ${ }^{1}$ The science and Technology Department, Tianjin Agricultural University \\ No.22, Jinjing Road, Xiqing District, Tianjin, 300384, China \\ ${ }^{2}$ The College of horticulture and landscape, Tianjin Agricultural University \\ No.22, Jinjing Road, Xiqing District, Tianjin, 300384, China \\ atjqingqingcao@163.com bjinghuiyang2@aliyun.com cqlizhang@163.com \\ d2485674628@qq.com
}

Keywords: Agriculture; Science and technology; Park

\begin{abstract}
In 2008, the construction of Binhai Agricultural Science and Technology Park was started in Tianjin.After nearly 10 years of efforts, 7 parks have been completed. In this paper, the construction of the park was summarized, some problems existing in the construction of the park were analyzed, and corresponding countermeasures were put forward to further enhance the construction of Binhai Agricultural Science and Technology Park in our city. The practical experience of park construction will provide an effective reference for the construction of agricultural science and technology park in the future.
\end{abstract}

\section{Introduction}

In order to implement the "Opinions on Implementation of the Integrated Development Strategy of Urban and Rural Areas to Speed up the Construction of a New Socialist Countryside" and developing modern agriculture in Binhai New Area, in 2008, The Tianjin Municipal Government General Office transmitted "the opinions on the promotion of Binhai Agricultural Science and Technology Parks construction by Municipal Agricultural Commission, Municipal Commission of Science and Technology ,Coastal City Commission" [1]. In the principle of prominent highlights, scientific and technological support, moderate scale, innovative mechanism and prominent benefits, the Binhai Agricultural Science and Technology Park was launched in the context of Binhai New Area. Binhai Agricultural Science and Technology Park will be built into an important base of agricultural science and technology innovation and achievement transformation and become the main form of modern agriculture in Binhai New Area. It will become an important engine for the development of modern agriculture in the whole city and become an important innovation base for radiating the Bohai Rim and even the whole country [2].

\section{Tianjin Binhai Agricultural Science and Technology Park Construction}

At present, seven coastal agricultural science and technology parks have been completed in Tianjin. Including the first batch of five plans: Binhai International Flower Science and Technology Park, Coastal Saline-alkali Plant Science and Technology Park, Binhai Chadian Grape Science and Technology Park, Binhai Ecological Agriculture Science and Technology Park, Binhai Ornamental Fish Science and Technology Park . In addition, two parks have newly established: Binhai Aolv Agriculture Science and Technology Park, Binhai Kuanda Ecological Agriculture Science and Technology Park. The total planned area is $1866.7 \mathrm{hm}^{2}$ with a total investment of 6.06 billion yuan. Each park received 10 million yuan supporting funds each year that provided by the Municipal Science and Technology Commission, Municipal Agriculture Commission and the Coastal 
Commission and provided 3 consecutive years, that each park received 90 million yuan supporting funds, the funds mainly be used for research and development platform, seedlings Breeding facilities and equipment, technical training, quality and safety testing equipment and road ditch supporting and afforestation and other infrastructure construction.

Even more gratifying is that the third batch of national agricultural science and technology parks were approved by the Ministry of Science and Technology in December 2010. Three parks: Binhai International Flower Science and Technology Park, Binhai Aolv Agricultural Science and Technology Park and Binhai Kuanda Ecological Agriculture and Technology Park, in view of the early good planning, investment and construction of the foundation, have become the main part of Tianjin Binhai National Agricultural Science and Technology Park building. The planned area of the core area of the park is $396.47 \mathrm{hm}^{2}$ with a total investment of 2.061 billion yuan. In the demonstration area ,the homestead land reclamation facilities agricultural park was build in Hua Ming town, etc, to promote facilities horticultural industry base in northern by the radiation zone. In 2015, the R \& D investment in the core area of the park reached 35.55 million yuan, seven times that of 2010. It has 1 national laboratories, 7 provincial and ministerial laboratories, and 3 academician expert workstations. The park realized a total output value of 893 million yuan and a net profit of 12.11 million yuan, driving around 4108 planted families and increasing their income by more than 1,800 yuan.

\section{Analysis of Problems in Tianjin Binhai Agricultural Science and Technology Park Construction}

\subsection{Land problems of the park}

At present, some parks have been embarrassed in determining the scale of land for construction purposes and land transfer. Enterprises in the park have acquired land use rights through such means as the transfer of land management rights, lease, anti-rent, and change of collective land to state-owned land. The procedures are quite complicated and not stable, companies are concerned about land use rights cannot be long-term [3]. In addition, the restrictions on the construction land quota lead to some necessary infrastructure facilities cannot keep up, but also lead to the enthusiasm of enterprises to enter the park is not high, investment difficulties.

\subsection{Construction master and operation mechanism}

Park construction master is the foundation of the park, Individual Park due to the master fuzzy, affecting the construction speed. At present, the construction master of the park is divided into enterprises and government departments. The mechanism of taking the enterprise as the master of the construction is relatively flexible and has an efficient management style. However, after all, the enterprises are based on efficiency first. They are not enthusiastic in some of the scientific and technological activities involving public welfare. In addition, integration of land resources has a certain degree of difficulty. However, with the government departments as the main body, the implementation of management system of the management committee system, production and management mechanism is not flexible enough; most of them are window to display, focusing on public welfare considerations, and the lack of a certain degree of operational capacity [4].

\subsection{Lack of long-term science and technology industry planning}

Binhai Agricultural Science and Technology Park is still in the initial stage of construction. Its positioning is focused on demonstration and promotion rather than industrialization of science and technology. It lacks understanding of the potentiality of industrialization of science and technology in the park and its far-reaching impact on the development of the park. There is no in-depth investigation of the industrialization of science and technology [5]. Although most of the parks have signed scientific and technological cooperation agreements with state-run scientific research institutes and well-known colleges and universities as technology support units, many of the 
cooperation with science and technology support units remain in the agreement, resulting in relatively loose relations and leading to weak capacity of independent innovation in most parks.

\subsection{Other problems}

First, the concept of understanding is not very clear. For the connotation of modern agricultural industrial park and other issues, some of the understanding is not yet clear, many parks are only efficient agriculture base or leading enterprises + bases. Second, the function is relatively simple. A considerable part of the park is limited to the production of agricultural products, processing, logistics, popular science training, the necessary public services and other functions are not in place. Third, the characteristic is not clear enough. Part of the park one-sided pursuit of attractive, stylish industrial projects, agricultural facilities, did not reflect the local characteristics and the implementation of the leading industry organizations. Fourth, park management and technical personnel are still relatively lacking. The construction and operation of the park is a systematic project, which requires more comprehensive management personnel and professional and technical personnel in a number of sectors. The reserve of talents in the park is slightly lagging behind.

\section{Countermeasures to Promote Tianjin Binhai Agricultural Science and Technology Park Construction}

\subsection{Comprehensively enhance the park construction level}

First, we must base ourselves on the advantages of local resources, focus on the dominant industries of local advantages and scientifically arrange the industrial development priorities of parks. Second, we must foster a group of competitors in the market. The advantage of park resources gathering is brought into play so that it can actively attract leading enterprises and farmers' cooperative organizations to start business in the park. We also have to speed up the cultivation of competitors in various markets. Thirdly, we need to build a group of well-known brands with strong competitiveness, and adhere to enhance product image, awareness of the park, and to promote the development of related industries by the brand [6]. At the same time, we must improve the transformation capacity of agricultural scientific and technological achievements. To introduce and absorb advanced scientific and technological achievements, adhere to a high starting point and high level, and adopt some encouraging measures to encourage scientific and technological personnel to bring achievements to business start-ups in the park [7].

\subsection{The development of the park needs government policy}

Different from the decentralized management of the family, the production in the park, a relatively large amount of land resources must be brought together to unify the operation planning and to unify the production layout. This involves many complicated links such as the change of the land contractual relationship and the secondary contract. In particular, it needs the township grass-roots government to coordinate the solution [8]. Some also involve the adjacent township and village land ownership issues, but also need to come forward to coordinate the higher government. It is necessary for the government to come forward to negotiate with and contract farmers in the demonstration area to unify their thinking and make unified planning adjustments to the layout of agricultural production. The government must provide the necessary supporting policies for the development of the agriculture in the park and effectively solve all the policy issues of concern to farmers so as to provide policy support for the development of the park.

\subsection{The development of the park must rely on more investment}

Infrastructure and follow-up investment is the fundamental guarantee for the healthy development of the park. In Binhai Agricultural Science and Technology Park, a large area, the original infrastructure is very weak, ditch, canal, road, water, electricity and other infrastructure needs to occupy a lot of money, because agricultural industry was relatively weak industry with a 
long return on investment, it is impossible to put an up-front investment of substantial financial resources. The required financial resources, in addition to the government's financial investment, should rely on the power of the community to invest in the development of the park. This needs to create an excellent environment for investment promotion, relax policies, lower the threshold, and carefully nurture enterprises in the park to nurture a batch of key enterprises as soon as possible.

\subsection{The deep development of the park needs to update the concept of production manager}

If the development of the park is simply a relative "concentration" of the agricultural production layout, it will seldom produce new benefits. Unlike traditional agriculture, agro-industrial parks have a large initial investment base and no relatively efficient returns, making it very difficult to achieve profitability in the short run. Therefore, the efficient return of agriculture must rely more on "integration" of agricultural technologies and agricultural industries. Such as increasing investment in agricultural research funding, improve the quality of agricultural products, good follow-up of fresh produce processing, extension of the park business scope of agricultural industry, the introduction of marketing concepts, the development of leisure and sightseeing functions and so on. Only with the simultaneous development of primary, secondary and tertiary industries, focusing on the construction of agro-ecological environment, the further development of agricultural brand efficiency and the development of additional agricultural production effects will result in a significant improvement in the overall efficiency of agricultural industrial park construction and will result in a stronger vitality.

\subsection{A variety of operating modes can be explored in park development}

The development of the park requires the support of government policies and funds. In the modern market economy and under the condition of proactively promoting industrial nurturing agriculture and cities driving rural areas, the development of agricultural science and technology parks can explore various modes of operation such as government guidance, enterprises running independently or relying on various agricultural colleges and universities, scientific research institutions, etc. joint development, but also the introduction of foreign investment development. Only in this way will we be able to increase the participation of "three sources" more and increase the enthusiasm of supporting agriculture and attract more non-agricultural funds to participate in agricultural development. [9]

\subsection{Strengthen personnel training and team formation}

The government should formulate and optimize policies for high-quality agricultural technicians entering the park to start businesses and attract and encourage outstanding talents from agricultural research institutes, higher agricultural colleges and agricultural extension units to join the park construction. Encourage some experts with agricultural technology and scientific research to participate in the park or set up an expert compound. Through strengthening technology development, cooperation and exchange, improve the overall scientific and technological level of the park. To ensure that the park has a number of strong technology, strong and strong contingent of experts as a sustainable and healthy development of the park backed [10].

At the same time, we should strengthen education and training of modern peasants. The development of modern agriculture must have a number of modern professional peasants who adapt to it. Existing agricultural practitioners are aging and women-oriented. Their ability to accept new technologies is not strong enough to meet the needs of the development of modern agriculture. We should take the construction of modern agricultural industrial parks as the starting point, strengthen the cultivation of agricultural talents, and speed up the cultivation of a number of modern peasant teams that meet the requirements of modern agricultural development. First, we must establish a modern farmer training base. In the park to establish a talent training center, a planned, organized arrangements for local farmers to carry out technical, management and other aspects of training. Actively attract local farmers to participate in the production of the park and enhance farmers' ability to develop modern agriculture. Second, we must cultivate modern agricultural science and 
technology personnel. Select middle-aged and young peasants with higher cultural qualifications as breeding target, let them directly participate in the production or management of the park, masters the production skills or management experience, and become the backbone of the development of modern agriculture. Through these backbone drives more peasants to increase wealth. Third, we must cultivate modern agricultural management personnel. Give full play to the leading role of all kinds of competitors in the market, and cultivate a group of new peasants who understand the operation and management of modern agriculture, and take over and set up a number of agricultural product marketing enterprises and farmer cooperative organizations to actively develop modern agricultural circulation and enhance competition in the agricultural market ability.

\section{Acknowledgement}

The research was sponsored by Tianjin key research project of tianjin municipal party committee (Project No.10-33)

\section{References:}

[1] The general office of the people's government of tianjin. The notice on the implementation of the construction work of binhai agricultural science and technology park by the commission of the commission of the municipal commission of the municipal commission of the municipal commission on the promotion of the construction of the coastal agricultural science and technology zone [R]. [2008], 2008.

[2] Xuequn Huang, Jin Li, Fuxu Lu et al. Research on supporting policy system of coastal agricultural science and technology park [J]. Tianjin agricultural science, 2014, 18(4):23-27.

[3] Bin Fang, Guanghai Lei, Youzhao Liu. The main problems of land in agricultural park [J]. China land, 2007,12:46

[4] Guangning Luo, Juan Sun, Tianye Xiao. Evaluation of development situation and innovation ability of national agricultural science park in guangdong [J]. Scientific and technological management research 2016 no.23:10 8-114.

[5] Peigang Cheng, Jinfeng Gu, Hualu Pan et al. Agricultural science and technology park is facing problems and restricting factors of the empirical analysis, based on the survey data of suzhou [J]. Science and technology management research, 2014) : 80-87 combine.

[6] Jiyi Li, Danni Yang. Countermeasures for the development of modern agricultural demonstration parks [J]. Rural economy and technology, 2013, 24(5) : 28-30.

[7] Xiufen Wei, Guoxing Sun, Shengxiong Wang et al. Play the countermeasures of the demonstration of tianjin agricultural science and technology park [J]. Tianjin economy, 2013,4:26-29.

[8] Xiufen Wei, Shengxiong Wang, Guoxing Sun. Tianjin agricultural science and technology park's main features, basic practices and demonstration driving mode [J], tianjin agricultural science, 2013,19 (4) : 47-50.

[9] Xuequn Huang, Jin Li, Guoxing Sun. The overall thinking and planning layout of the construction of agricultural science park in tianjin $[\mathrm{J}]$. China agricultural resources and regionalization, 2004,25(3)38-41.

[10] Lijuan Wang, Shujin Wang. Analysis of operation mode and performance relation of modern agricultural industrial park [J]. Scientific management research, 2013, 30(1) : 117-120. 